\title{
Versatile Picklocks to Access All Opioid Receptors: Tuning the Selectivity and Functional Profile of the Cyclotetrapeptide c[Phe-D-Pro-Phe-Trp] $(\mathrm{CJ}-15,208)$
}

Rossella De Marco, ${ }^{\dagger}$ Andrea Bedini, ${ }^{\dagger}$ Santi Spampinato, ${ }^{+8}$ Lorenzo Cavina,${ }^{\dagger}$ Edoardo Pirazzoli, ${ }^{\dagger}$ and Luca Gentilucci $^{\dagger} *$

${ }^{\dagger}$ Department of Chemistry “G. Ciamician”, University of Bologna, via Selmi 2, 40126 Bologna, Italy.

${ }^{*}$ Department of Pharmacy and Biotechnology, University of Bologna, via Irnerio 48, 40126 Bologna, Italy

* E-mail: luca.gentilucci@ unibo.it; Tel: +39 0512099570; Fax: +39 0512099456; http://www.ciam.unibo.it/gentilucci

§E-mail: santi.spampinato@unibo.it; Tel: +39 0512091851.

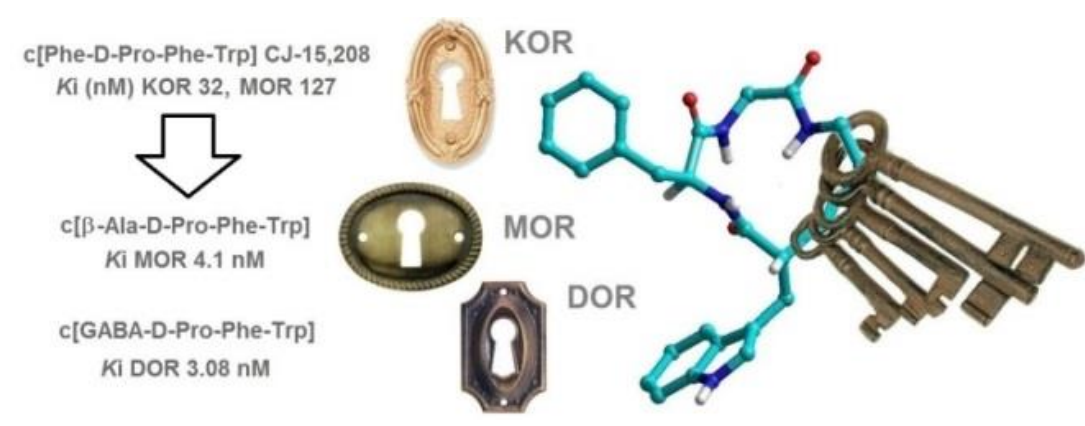

KEYWORDS cyclotetrapeptide; opioid receptor; antinociception; $\beta$-amino acid; $\gamma$-amino acid; conformational analysis; opioid agonist.

\section{Table of contents}

Peptide synthesis

Table S1. Analysis of the linear precursors, and cyclization yields

p. S4

Analytical characterization of CTPs 1, 5-8

Figure S1. RP-HPLC/ESI MS of 9.

Figure S2. ${ }^{1} \mathrm{H}$ NMR of $\mathbf{1}$ and $\mathbf{9 .}$

Biochemical characterizations

p. S9

Conformational analysis of 1, 9A, 9B, 10 


\section{General Methods.}

Standard chemicals and biological reagents were purchased from commercial sources and used without further purification. Cell culture media, phosphate-buffered saline (PBS) and fetal bovine serum (FBS), from Lonza; black 96-well clear-bottom plates were purchased from Corning Costar. HEK-293 cells from ATCC, USA; plasmids from UMR cDNA Research Center, USA; cAMP EIA kit from Cayman Chemical Co., Ann Arbor, MI, U.S. Adult male CD-1 mice from Charles River, Calco, Como, Italy. The MW-assisted synthesis was performed using a MicroSYNTH microwave lab station equipped with a built-in ATC-FO advanced fiber optic automatic temperature control. Flash chromatography was performed on silica gel (230-400 mesh), using mixtures of distilled solvents. Purities were determined to be $>95 \%$ by analytical RP HPLC and elemental analysis. RP HPLC was performed on an Agilent 1100 series apparatus, using a RP column Phenomenex mod. Gemini $3 \mu \mathrm{C} 18110 \AA 10033.0$ mm (P/No 00D-4439-Y0); column description: stationary phase octadecyl carbon chain-bonded silica (C18) with TMS endcapping, fully porous organosilica solid support, particle size $3 \mathrm{~mm}$, pore size $110 \AA$, length $100 \mathrm{~mm}$, internal diameter $3 \mathrm{~mm}$; DAD 210 $\mathrm{nm}$; mobile phase from 9:1 $\mathrm{H}_{2} \mathrm{O} / \mathrm{CH}_{3} \mathrm{CN}$ to $2: 8 \mathrm{H}_{2} \mathrm{O} / \mathrm{CH}_{3} \mathrm{CN}$ in 20 min at a flow rate of $1.0 \mathrm{~mL} \mathrm{~min}^{-1}$, followed by $10 \mathrm{~min}$ at the same composition. Direct-phase HPLC analysis was performed on an Agilent 1100 series apparatus, using a Kromasil 60-5Diol column (P/No E42500); column description: stationary phase silica, particle size $5 \mu \mathrm{m}$, pore size $60 \AA$, length $250 \mathrm{~mm}$, internal diameter $4.6 \mathrm{~mm}$, DAD $210 \mathrm{~nm}$; mobile phase hexane/2-propanol 60:40, at a flow rate of $0.6 \mathrm{~mL} \mathrm{~min}^{-1}$. Semi-preparative RP-HPLC of cyclic compounds was performed on an Agilent 1100 series apparatus, using a RP column ZORBAX mod. Eclipse XDBC18 PrepHT cartridge $21.23150 \mathrm{~mm} 7 \mu$ (P/No 977150-102); column description: stationary phase octadecyl carbon chain-bonded silica (C18), double end-capped, particle size $7 \mathrm{~mm}$, pore size $80 \AA$, lenght $150 \mathrm{~mm}$, internal diameter $21.2 \mathrm{~mm}$; DAD $210 \mathrm{~nm}$; mobile phase from 8:2 $\mathrm{H}_{2} \mathrm{O}-\mathrm{CH}_{3} \mathrm{CN}$ to $100 \% \mathrm{CH}_{3} \mathrm{CN}$, in

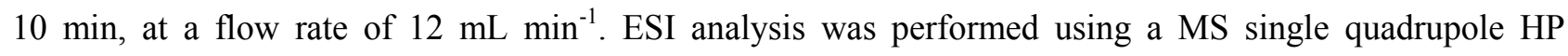
1100MSD detector, with a drying gas flow of $12.5 \mathrm{~L} \mathrm{~min}^{-1}$, nebulizer pressure 30 psgi, drying gas temp. $350^{\circ} \mathrm{C}$, capillary voltage 4500 (1) and 4000 (2), scan 50-2600 amu. Elemental analyses were performer using a Thermo Flash $2000 \mathrm{CHNS} / \mathrm{O}$ analyzer. ${ }^{1} \mathrm{H}$ NMR spectra were recorded using a Varian Gemini apparatus at $400 \mathrm{MHz}$ in $5 \mathrm{~mm}$ tubes, using $0.01 \mathrm{M}$ peptide in 8:2 [D6]DMSO$/ \mathrm{H}_{2} \mathrm{O}$ at r.t. Water suppression was performed by the solvent presaturation procedure implemented in Varian (PRESAT). ${ }^{13} \mathrm{C}$ NMR spectra were recorded at $100 \mathrm{MHz}$. Chemical shifts are reported as $\delta$ values relative to residual DMSO $\delta H$ (2.50 p.p.m.) as internal standard. The unambiguous assignment of ${ }^{1} \mathrm{H}$ NMR resonances was performed by $2 \mathrm{D}$ gCOSY. VT${ }^{1} \mathrm{H}$ NMR experiments were performed over the range of 298-348 K; temperature calibration was done with the ethylene glycol OHCHn chemical-shift separation method.

Solid-phase synthesis of the linear precursors. The linear peptides were assembled by MW-assisted SPPS on a commercially available Wang resin preloaded with the first residue, using Fmoc-protected amino acids, and TBTU/HOBt/DIPEA as coupling agents. All steps were performed according to the following general procedures. 
Fmoc deprotection. The Fmoc-Phe-preloaded resin ( $0.5 \mathrm{~g}$, Phe loading $0.4-0.8 \mathrm{mmol} / \mathrm{g}$ ) was treated with $20 \%$ piperidine in DMF $(5 \mathrm{~mL})$ for 2 min under MW irradiation at $40 \mathrm{~W}$, monitoring the internal temperature at $45^{\circ} \mathrm{C}$ with a built-in ATC-FO advanced fiber optic automatic temperature control. The suspension was filtered and the resin was washed with DCM $(5 \mathrm{~mL})$ and treated with a second portion of $20 \%$ piperidine in DMF under MW irradiation as described above. The suspension was then filtered, and the resin was washed three times in sequence with DCM (5 mL), MeOH (5 mL), and DMF (5mL).

Peptide bond formation. The resin was swollen in DCM (5 mL), and Fmoc-amino acid (0.6 mmol), the coupling reagents HBTU $(0.6 \mathrm{mmol})$, HOBt $(0.6 \mathrm{mmol})$, DIPEA $(1.2 \mathrm{mmol})$, were added under a nitrogen atmosphere to the resin, and the mixture was reacted while bubbling $\mathrm{N}_{2}$ for $10 \mathrm{~min}$, under MW irradiation at $45^{\circ} \mathrm{C}$ as described above. The resin was washed in sequence 3 times with DCM $(5 \mathrm{~mL}), \mathrm{MeOH}(5 \mathrm{~mL})$, and DMF $(5 \mathrm{~mL})$, and coupling efficacy was determined by means of the Kaiser or chloranil tests (for coupling on Pro).

Peptide cleavage. The resulted peptidyl resin was treated with a mixture of TFA and TIPS/water/PhOH as scavengers $(7: 1: 1: 1 \mathrm{v} / \mathrm{v}, 15 \mathrm{~mL})$, for 2 hours at r.t. The mixture was filtered, and the resin was washed 3 times with $5 \%$ TFA in $\mathrm{Et}_{2} \mathrm{O}(10 \mathrm{~mL})$. The filtrate and the washes were collected and solvent and volatiles were removed at r.t. under $\mathrm{N}_{2}$ flow. The resulting residue was suspended in ice-cold $\mathrm{Et}_{2} \mathrm{O}$, and the crude solid which precipitated was triturated and collected by centrifuge. The purity of the product was determined $69-84 \%$ by RP HPLC (for the conditions, see General Methods), and their identity was assessed by electrospray ESI MS (Table S1).

Cyclization. The crude linear peptide $(0.1 \mathrm{mmol})$ in DMF $(5 \mathrm{~mL})$ was added over $12 \mathrm{~h}$ using a KD Scientific single infusion syringe pump and a $10 \mathrm{~mL}$ syringe, to a solutionof HATU (0.4 mmol) and DIEA $(1.0 \mathrm{mmol})$ in DMF $(20 \mathrm{~mL})$. The reaction was allowed to stir for an additional $12 \mathrm{~h}$. The solvent was removed at reduced pressure, the residue was dissolved in EtOAc $(25 \mathrm{~mL})$, and the mixture was washed twice with $1 \mathrm{~N}$ citric acid $(5 \mathrm{~mL})$, saturated bicarbonate $(5 \mathrm{~mL})$ and brine $(5 \mathrm{~mL})$. The organic layer was dried over $\mathrm{Na}_{2} \mathrm{SO}_{4}$, and the solvent was removed under reduced pressure. The resulting crude residues were purified by semi-preparative RP HPLC (see General Methods). Purities were determined to be $>95 \%$ by analytical RP HPLC and elemental analysis (for the conditions, see General Methods). The identity of the compounds was confirmed by ${ }^{1} \mathrm{H}$ NMR, 2D gCOSY, ${ }^{13} \mathrm{C}$ NMR, and ESI MS analyses. 
Table S1. RP HPLC and ESI MS analyses of the linear precursors and of the CTPs $\mathbf{1}$ and 5-10, and respective cyclization yields.

\begin{tabular}{|c|c|c|c|c|c|c|c|c|c|}
\hline Linear peptide sequence & $\begin{array}{l}\mathrm{Rt} \\
(\min )^{[\mathrm{a}]}\end{array}$ & $\begin{array}{l}\text { Purity } \\
(\%)^{[\mathrm{a}]}\end{array}$ & $\begin{array}{l}\text { ESI MS }[M+1] \\
\text { found/calcd. }{ }^{[b]}\end{array}$ & CTP & CTP sequence & $\begin{array}{l}\text { Cyclization } \\
\text { Yield }(\%)^{[c]}\end{array}$ & $\begin{array}{l}\text { ES-MS }[\mathrm{M}+1] \\
\text { found/calcd. }{ }^{[\mathrm{b}]}\end{array}$ & $\begin{array}{l}\text { Rt } \\
(\min )^{[\mathrm{d}]}\end{array}$ & $\begin{array}{l}\text { Purity } \\
(\%)^{[\mathrm{d}]}\end{array}$ \\
\hline H-Trp-Phe-D-Pro-Phe-OH & 1.74 & 70 & $596.3 / 596.3$ & 1 & c[Phe-D-Pro-Phe-Trp] & 77 & $578.5 / 578.3$ & 7.28 & 98 \\
\hline H-(1-MeTrp)-Phe-D-Pro-Phe-OH & 1.94 & 72 & $610.2 / 610.3$ & 5 & c[Phe-D-Pro-Phe-(1-MeTrp)] & 75 & $592.4 / 592.3$ & 8.82 & 97 \\
\hline H-D-(1-MeTrp)-Phe-D-Pro-Phe-OH & 1.96 & 73 & $610.2 / 610.3$ & 6 & c[Phe-D-Pro-Phe-D-(1-MeTrp)] & 74 & $592.5 / 592.3$ & 10.79 & 96 \\
\hline H-Trp-D-Ala-D-Pro-Phe-OH & 1.30 & 79 & $520.3 / 520.3$ & 7 & $\mathrm{c}$ [ala-D-Pro-Phe-Trp] & 65 & $502.4 / 502.3$ & 5.84 & 95 \\
\hline H-Trp-Ala-D-Pro-D-Phe-OH & 1.36 & 78 & $520.2 / 520.3$ & 8 & c[Ala-D-Pro-D-Phe-Trp] & traces & $502.4 / 502.3$ & 5.30 & - \\
\hline H-Ala-D-Pro-D-Phe-Trp-OH ${ }^{[\mathrm{e}]}$ & 1.44 & 82 & $520.2 / 520.3$ & 8 & $\mathrm{c}[\text { Ala-D-Pro-D-Phe-Trp }]^{[\mathrm{e}]}$ & $55^{[\mathrm{e}]}$ & $502.4 / 502.3$ & 5.31 & $95 \%^{[\mathrm{f}]}$ \\
\hline H-Trp- $\beta$-Ala-D-Pro-Phe-OH & 1.49 & 84 & $520.2 / 520.3$ & 9 & $c[\beta$-Ala-D-Pro-Phe-Trp $]$ & 95 & $502.2 / 502.3$ & 6.63 & 98 \\
\hline H-Trp-GABA-D-Pro-Phe-OH & 1.55 & 69 & $534.3 / 534.3$ & 10 & $\mathrm{c}$ [GABA-D-Pro-Phe-Trp] & 94 & $516.3 / 516.3$ & 6.02 & 97 \\
\hline
\end{tabular}

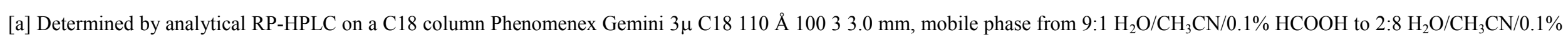

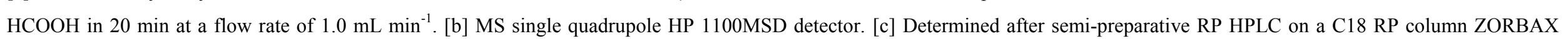

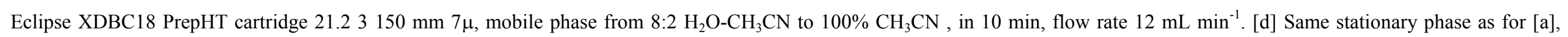

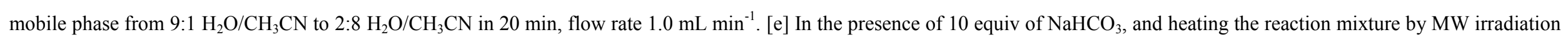
$\left(45^{\circ} \mathrm{C}\right)$ for $10 \mathrm{~min}$ before quenching. [f] To improve purity, 8 was pre-purified by flash chromatography over silica gel (eluent: MeOH/EtOAc $\left.95: 5\right)$ prior to semi-preparative RP HPLC. 
c[Trp-Phe-D-Pro-Phe] (CJ-15,208) 1. ${ }^{1} \mathrm{H}$ NMR $\left(400 \mathrm{MHz}, 8: 2\right.$ [D6]DMSO/H $\left.\mathrm{H}_{2} \mathrm{O}\right) \delta: 1.67$ (m, 1H, DProH $\gamma$ ), 1.78 (m, 1H, D-ProH $\gamma$ ), 1.93 (m, 1H, D-ProH $\beta$ ), 2.22 (m, 1H, D-ProH $\beta$ ), 2.54 (dd, J = 3.9, 14.0 Hz, 1H, TrpH $\beta$ ), 2.83-2.93 (m, 2H, Phe ${ }^{1} \mathrm{H} \beta+\operatorname{TrpH} \beta$ ), 2.95-3.00 (m, 2H, Phe ${ }^{1} \mathrm{H} \beta+\mathrm{Phe}^{3} \mathrm{H} \beta$ ), 3.11 (dd, J = 1.5, 11.6 Hz, 1H, Phe ${ }^{3} \mathrm{H} \beta$ ), 3.35-3.45 (m, 2H, D-ProH $\delta$ ), 3.92 (dt, J = 7.6, 8.8 Hz, 1H, Phe ${ }^{1} \mathrm{H \alpha}$ ), 4.19 (ddd, J = 3.9, 7.2, 10.6 Hz, 1H, TrpH $\alpha$ ), $4.64\left(\mathrm{dt}, \mathrm{J}=1.5,8.2 \mathrm{~Hz}, 1 \mathrm{H}, \mathrm{Phe}^{3} \mathrm{H} \alpha\right.$ ), 5.32 (dd, J = 1.0, 6.4 Hz, 1H, D-ProH $\alpha$ ), $6.88\left(\mathrm{~d}, \mathrm{~J}=6.4 \mathrm{~Hz}, 2 \mathrm{H}, \operatorname{Phe}^{1} \mathrm{ArH}_{2,6}\right), 6.92\left(\mathrm{~s}, 1 \mathrm{H}, \operatorname{Trp} \mathrm{ArH}_{2} \text { ), } 6.97 \text { (dd, J = 7.2, 7.6 Hz, 1H, TrpArH }\right)_{5}$, 7.01$7.11\left(\mathrm{~m}, 4 \mathrm{H}, \mathrm{Phe}^{1} \mathrm{ArH}_{3-5}+\operatorname{TrpArH}\right)_{6}, 7.21\left(\mathrm{dd}, \mathrm{J}=7.2,7.6 \mathrm{~Hz}, 1 \mathrm{H}, \mathrm{Phe}^{3} \mathrm{ArH}_{4}\right), 7.30(\mathrm{dd}, \mathrm{J}=7.2,7.6 \mathrm{~Hz}, 2 \mathrm{H}$, $\operatorname{Phe}^{3} \mathrm{ArH}_{3,5}$ ), 7.34 (d, J = 8.0 Hz, 1H, TrpArH $)_{7}, 7.54$ (d, J = 7.2 Hz, 2H, $\operatorname{Phe}^{3} \operatorname{ArH}_{2,6}$ ), 7.63 (d, J = 7.2 Hz, 1H, TrpArH ${ }_{4}$ ), 8.30 (br.d, 1H, Phe ${ }^{3} \mathrm{NH}$ ), 8.75 (d, J = 7.2 Hz, 1H, TrpNH), 9.02 (br.s, 1H, Phe ${ }^{1} \mathrm{NH}$ ), 10.83 (s, 1H, $\left.\mathrm{TrpH}_{1}\right) ;{ }^{13} \mathrm{C}$ NMR (100 MHz, 8:2 [D6]DMSO/H $\left.\mathrm{H}_{2} \mathrm{O}\right) \delta: 20.8,27.3,32.8,36.1,37.7,49.1,57.3,58.4,58.9$, $60.0,79.7,111.1,111.7,118.8,118.9,121.3,123.7,126.8,127.0,127.8,128.6,136.6,172.8,173.1$; ESI MS $(\mathrm{m} / \mathrm{z}) 578.5[\mathrm{M}+1]$, calcd 578.3; Elem. Anal. for $\mathrm{C}_{34} \mathrm{H}_{35} \mathrm{~N}_{5} \mathrm{O}_{4}$ : calcd C 70.69, H 6.11, N 12.12; found C 69.73, H 6.06, N 12.16.

c[Phe-D-Pro-Phe-(1-Me-Trp)] 5. ${ }^{1} \mathrm{H}$ NMR (400 MHz, 8:2 [D6]DMSO/ $\left.\mathrm{H}_{2} \mathrm{O}\right) \delta: 1.68$ (m, 1H, D-ProH $\gamma$ ), 1.79 (m, 1H, D-ProH $\gamma), 1.90$ (m, 1H, D-ProH $\beta$ ), 2.20 (m, 1H, D-ProH $\beta$ ), 2.55 (dd, J = 4.0, $13.8 \mathrm{~Hz}, 1 \mathrm{H}$, $\operatorname{TrpH} \beta$ ), 2.80-3.00 (m, $4 \mathrm{H}, \mathrm{Phe}^{1} \mathrm{H} \beta+\operatorname{TrpH} \beta+\mathrm{Phe}^{3} \mathrm{H} \beta$ ), 3.10 (dd, J = 2.0, $11.4 \mathrm{~Hz}, 1 \mathrm{H}, \mathrm{Phe}^{3} \mathrm{H} \beta$ ), 3.37-3.46 (m,

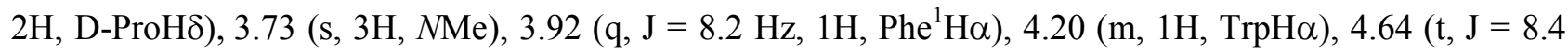

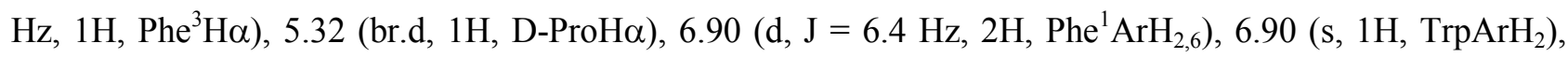
6.98-7.11 (m, 5H, Phe $\left.{ }^{1} \mathrm{ArH}_{3-5} \operatorname{TrpArH}_{5}+\mathrm{TrpArH}_{6}\right), 7.20$ (dd, J = 7.2, 7.6 Hz, 1H, Phe $\left.{ }^{3} \mathrm{ArH}_{4}\right), 7.30-7.36(3 \mathrm{H}$, $\mathrm{Phe}^{3} \mathrm{ArH}_{3,5}+\operatorname{TrpArH}_{7}$ ), 7.55 (d, J = 7.4 Hz, 2H, $\mathrm{Phe}^{3} \mathrm{ArH}_{2,6}$ ), 7.63 (d, J = 7.0 Hz, 1H, TrpArH $)_{4}$, 8.32 (br.d, 1H, Phe ${ }^{3} \mathrm{NH}$ ), 8.78 (d, J = $\left.7.2 \mathrm{~Hz}, 1 \mathrm{H}, \mathrm{TrpNH}\right), 8.99$ (br.s, $\left.1 \mathrm{H}, \mathrm{Phe}^{1} \mathrm{NH}\right) ;{ }^{13} \mathrm{C} \mathrm{NMR}(100 \mathrm{MHz}, 8: 2$ [D6]DMSO $\left./ \mathrm{H}_{2} \mathrm{O}\right) \delta: 24.1,28.0,29.5,33.9,37.6,37.8,48.4,56.3,59.3,60.2,68.1,108.2,110.0,119.0$, $119.3,122.0,124.2,126.0,128.3,128.6,128.7,136.9,137.4,171.4,172.5,172.7,173.0$; ESI MS (m/z) $592.4[\mathrm{M}+1]$, calcd 592.3; Elem. Anal. for $\mathrm{C}_{35} \mathrm{H}_{37} \mathrm{~N}_{5} \mathrm{O}_{4}$ : calcd C 71.05, H 6.30, N 11.84; found: C 70.99, $\mathrm{H}$ $6.26, \mathrm{~N} 11.85$.

c[Phe-D-Pro-Phe-D-(1-MeTrp)] 6. ${ }^{1} \mathrm{H}$ NMR (400 MHz, 8:2 [D6]DMSO/H $\left.{ }_{2} \mathrm{O}\right) \delta: 1.60$ (m, 1H, D-ProH $\beta$ ), 1.76 (m, 1H, D-ProH $\gamma), 1.96$ (m, 1H, D-ProH $\gamma), 2.15$ (m, 1H, D-ProH $)$ ), 2.69-2.79 (m, 2H, D$\left.\operatorname{TrpH} \beta+\mathrm{Phe}^{3} \mathrm{H} \beta\right), 2.86\left(\mathrm{dd}, \mathrm{J}=7.0,13.0 \mathrm{~Hz}, 1 \mathrm{H}, \mathrm{Phe}^{1} \mathrm{H} \beta\right.$ ), 2.99-3.06 (m, 2H, Phe ${ }^{1} \mathrm{H} \beta+\mathrm{Phe}^{3} \mathrm{H} \beta$ ), 3.08 (dd, $\mathrm{J}=$

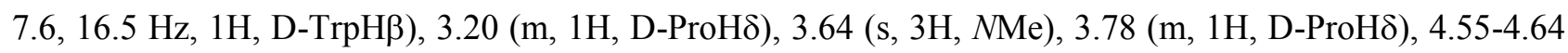
(m, 2H, Phe $\left.{ }^{3} \mathrm{H} \alpha+\mathrm{D}-\mathrm{TrpH} \alpha\right), 4.67$ (dd, J = 1.8, 7.6 Hz, 1H, D-ProH $\alpha$ ), 4.90 (dt, J = 7.2, 9.6 Hz, 1H, Phe $\left.{ }^{1} \mathrm{H} \alpha\right)$, 6.86 (s, 1H, D-TrpArH $)_{2}, 6.98$ (dd, J = 7.2, 7.6 Hz, 1H, D-TrpArH ) 7.12 (t, J = 7.6 Hz, 1H, D-TrpArH $)_{6}$, 7.14-7.29 $\left(\mathrm{Phe}^{1} \mathrm{ArH}+\mathrm{Phe}^{3} \mathrm{ArH}\right), 7.34\left(\mathrm{~d}, \mathrm{~J}=8.0 \mathrm{~Hz}, 1 \mathrm{H}, \mathrm{D}-\operatorname{TrpArH}_{7}\right), 7.47\left(\mathrm{~m}, 3 \mathrm{H}, \mathrm{Phe}^{1} \mathrm{NH}+\mathrm{Phe}{ }^{3} \mathrm{NH}\right.$ $\left.+\operatorname{TrpArH}{ }_{4}\right), 8.63(\mathrm{~d}, \mathrm{~J}=8.8 \mathrm{~Hz}, 1 \mathrm{H}, \mathrm{D}-\mathrm{TrpNH}) ;{ }^{13} \mathrm{C} \mathrm{NMR}(100 \mathrm{MHz}, 8: 2$ [D6]DMSO/H $2 \mathrm{O}) \delta: 24.1,25.8$, 30.2, 33.6, 36.4, 36.8, 50.0, 55.1, 58.1, 62.2, 65.2, 110.7, 118.8 119.6, 121.7, 127.5, 127.7, 128.4, 128.7, 129.5 129.6, 137.5, 138.7, 167.7, 172.3, 173.8, 174.0; ESI MS (m/z) 592.3 [M+1], calcd 592.3; Elem. Anal. for $\mathrm{C}_{35} \mathrm{H}_{37} \mathrm{~N}_{5} \mathrm{O}_{4}$ : calcd C 71.05, H 6.30, N 11.84; found: C 70.94, H 6.26, N 11.85. 
c[D-Ala-D-Pro-Phe-Trp] 7. ${ }^{1} \mathrm{H}-\mathrm{NMR}\left(400 \mathrm{MHz}, 8: 2\right.$ [D6]DMSO/H $\left.\mathrm{H}_{2} \mathrm{O}\right) \delta: 1.05(\mathrm{~d}, \mathrm{~J}=7.0 \mathrm{~Hz}, 3 \mathrm{H}, \mathrm{D}-$ AlaMe), 1.40-1.55 (m, 2H, D-ProH $\gamma$ ), 1.59 (m, 1H, D-ProH $\beta$ ), 1.92 (m, 1H, D-ProH $\beta$ ), 2.80-3.15 (m, 4H, $\operatorname{TrpH} \beta+\operatorname{PheH} \beta$ ), 3.38-3.56 (m, 2H, D-ProH $\delta$ ), 3.95-4.01 (m, 2H, TrpH $\alpha+\mathrm{PheH} \alpha), 4.55$ (m, 1H, D-AlaH $\alpha$ ),

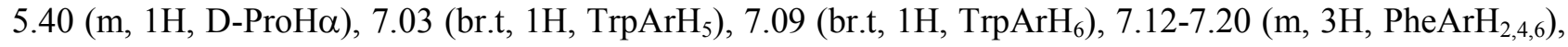
7.20-7.36 (m, 3H, TrpArH $\left.\left.{ }_{2}+\operatorname{PheArH}_{3,5}\right), 7.33(\mathrm{~d}, \mathrm{~J}=8.0 \mathrm{~Hz}, 1 \mathrm{H}, \operatorname{TrpArH})_{7}\right) 7.47(\mathrm{~d}, \mathrm{~J}=8.8 \mathrm{~Hz}, 1 \mathrm{H}$, $\left.\operatorname{TrpArH}_{4}\right), 7.84$ (d, J = 8.8 Hz, 1H, D-AlaNH), 8.18 (d, J = 6.6 Hz, 1H, PheNH), 8.33 (d, J =9.0 Hz, 1H,

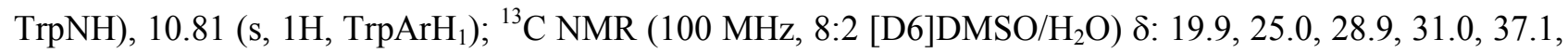
48.9, 49.2, 61.0, 61.5, 66.6, 110.0, 112.0, 119.2, 120.1 122.4, 123.0, 126.0, 128.3, 129.5, 134.7, 135.8, 170.1, 171.6, 173.0, 173.5; ES-MS (m/z) 502.3 [M+1], calcd 502.2; Elem. Anal. for $\mathrm{C}_{28} \mathrm{H}_{31} \mathrm{~N}_{5} \mathrm{O}_{4}$ : calcd C 67.05, $\mathrm{H}$ 6.23, N 13.96; found C 66.99, H 6.21, N 14.00.

c[Ala-D-Pro-D-Phe-Trp] 8. ${ }^{1} \mathrm{H}-\mathrm{NMR}(400 \mathrm{MHz}, 8: 2$ [D6]DMSO/H $2 \mathrm{O}) \delta: 1.10(\mathrm{~d}, \mathrm{~J}=6.9 \mathrm{~Hz}, 3 \mathrm{H}, \mathrm{AlaMe})$, 1.40-1.95 (m, 4H, D-ProH $\gamma+\mathrm{D}-\operatorname{ProH} \beta$ ), 2.82-3.25 (m, 4H, TrpH $\beta+\mathrm{D}-\mathrm{PheH} \beta$ ), 3.40-3.55 (m, 2H, D-ProH $)$ ),

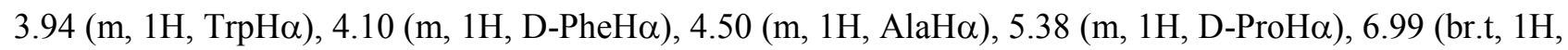
$\operatorname{Trp} \mathrm{ArH}_{5}$ ), 7.05 (br.t, $1 \mathrm{H}, \operatorname{TrpArH}{ }_{6}$ ), 7.12-7.34 (m, 6H, $\left.\operatorname{TrpArH}_{2}+\mathrm{D}-\mathrm{PheArH}\right), 7.35$ (d, J = 8.0 Hz, 1H, $\operatorname{TrpArH}_{7}$ ), 7.49 (d, J = 9.0 Hz, 1H, TrpArH ${ }_{4}$ ), 7.80 (br.d, 1H, AlaNH), 8.20 (br.d, D-PheNH), 8.40 (br.d, 1H,

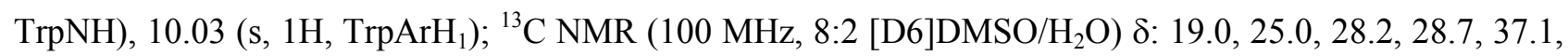
49.6, 49.9, 58.8, 59.9, 66.5, 108.4, 110.5, 119.0, 119.3, 121.3, 122.5, 124.6, 127.4, 127.5, 128.0, 135.7, 135.8, 171.3, 172.1, 172.8, 172.9; ES-MS (m/z) 502.4 [M+1], calcd 502.2; Elem. Anal. for $\mathrm{C}_{28} \mathrm{H}_{31} \mathrm{~N}_{5} \mathrm{O}_{4}$ : calcd C 67.05, H 6.23, N 13.96; found C 66.94, H 6.19, N 14.04.

$\mathrm{c}\left[\beta\right.$-Ala-D-Pro-Phe-Trp] 9. ${ }^{1} \mathrm{H}$ NMR (two sets of signals in $\sim 2: 1$ ratio, $>=$ major isomer, $<=$ minor isomer; see the SI) $\delta: 1.76\left(\mathrm{~m}, 1 \mathrm{H}_{<}, \mathrm{D}-\mathrm{ProH} \beta_{<}\right), 1.78-1.93\left(\mathrm{~m}, 3 \mathrm{H}_{>}+2 \mathrm{H}_{<}, 2 \times \mathrm{D}-\mathrm{ProH} \beta_{>}+\mathrm{D}-\mathrm{ProH} \gamma_{>}+2 \times \mathrm{D}-\right.$ $\left.\operatorname{ProH} \gamma_{<}\right), 1.97\left(\mathrm{~m}, 1 \mathrm{H}_{<}, \beta \mathrm{AlaH} \alpha_{<}\right), 2.09\left(\mathrm{~m}, 1 \mathrm{H}_{>}, \mathrm{D}-\operatorname{ProH} \gamma_{>}\right), 2.23\left(\mathrm{~m}, 1 \mathrm{H}_{<}, \mathrm{D}-\operatorname{ProH} \beta_{<}\right), 2.33\left(\mathrm{~m}, 1 \mathrm{H}_{<}\right.$, $\left.\beta \mathrm{AlaH} \alpha_{<}\right), 2.45\left(\mathrm{~m}, 1 \mathrm{H}_{>}, \beta \mathrm{AlaH} \alpha_{>}\right), 2.58\left(\mathrm{~m}, 1 \mathrm{H}_{>}, \beta \mathrm{AlaH} \alpha_{>}\right), 2.81-2.86\left(\mathrm{~m}, 2 \mathrm{H}_{>}, \mathrm{PheH} \beta_{>}\right), 2.87-2.92(\mathrm{~m}$, $\left.2 \mathrm{H}_{<}, \operatorname{PheH} \beta_{<}\right), 2.92-3.00\left(\mathrm{~m}, 2 \mathrm{H}_{>}+1 \mathrm{H}_{<}, \beta \mathrm{AlaH} \beta_{>}+\operatorname{TrpH} \beta_{>}+\operatorname{TrpH} \beta_{<}\right), 3.02-3.12\left(\mathrm{~m}, 2 \mathrm{H}_{<}, \operatorname{TrpH} \beta_{<}+\beta A l a H \beta_{<}\right)$, $3.24\left(\mathrm{dd}, \mathrm{J}=7.8,14.2 \mathrm{~Hz}, 1 \mathrm{H}>, \operatorname{TrpH} \beta_{>}\right), 3.35\left(\mathrm{~m}, 1 \mathrm{H}_{<}, \mathrm{D}-\mathrm{ProH} \delta_{<}\right), 3.45-3.52\left(\mathrm{~m}, 2 \mathrm{H}_{>}+1 \mathrm{H}_{<}, 2 \times \mathrm{D}-\right.$ ProH $\left.\delta_{>}+\mathrm{D}-\operatorname{ProH} \delta_{<}\right), 3.69-3.76\left(\mathrm{~m}, 1 \mathrm{H}>+1 \mathrm{H}<, \beta \mathrm{AlaH} \beta_{>}+\operatorname{TrpH} \alpha_{<}\right), 3.81\left(\mathrm{~m}, 1 \mathrm{H}_{<}, \beta \mathrm{AlaH} \beta_{<}\right), 4.14\left(\mathrm{~m}, 1 \mathrm{H}_{>}\right.$, PheH $\left.\alpha_{>}\right), 4.19\left(\mathrm{~m}, 1 \mathrm{H}_{<}, \mathrm{PheH} \alpha_{<}\right), 4.31\left(\mathrm{~m}, 1 \mathrm{H}_{>}, \mathrm{TrpH} \alpha_{>}\right), 4.50\left(\mathrm{~m}, 1 \mathrm{H}_{<}, \mathrm{D}-\mathrm{ProH} \alpha_{<}\right), 4.53$ (m, 1H $\mathrm{H}_{>}, \mathrm{D}-$ ProH $\alpha$ ) , 6.62-6.71 (m, $\left.2 \mathrm{H}_{<}, \operatorname{TrpArH}_{2<}+\beta \mathrm{AlaNH}_{<}\right), 6.89$ (br.t, $\left.1 \mathrm{H}_{>}, \beta A l a N H_{>}\right), 6.94\left(\mathrm{t}, \mathrm{J}=7.2 \mathrm{~Hz}, 1 \mathrm{H}_{<}\right.$, $\left.\operatorname{TrpArH}_{5<}\right), 9.98\left(\mathrm{dd}, \mathrm{J}=7.2,8.0 \mathrm{~Hz}, 1 \mathrm{H}_{>}, \operatorname{TrpArH}_{5>}\right), 9.99-7.09\left(\mathrm{~m}, 2 \mathrm{H}_{>}+1 \mathrm{H}_{<}, \operatorname{TrpArH}_{6<}+\operatorname{TrpArH}_{2>}\right.$

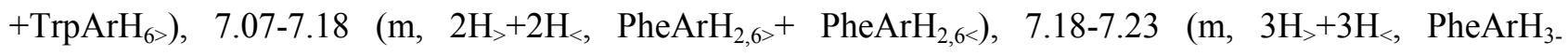
$\left.{ }_{5>}+\mathrm{PheArH}_{3-5<}\right), 7.26-7.33\left(\mathrm{~m}, 1 \mathrm{H}_{>}+1 \mathrm{H}_{<}, \operatorname{TrpArH}_{7>}+\operatorname{TrpArH}_{7>}\right), 7.40\left(\mathrm{~d}, \mathrm{~J}=7.6 \mathrm{~Hz}, 1 \mathrm{H}_{<}, \operatorname{TrpArH}_{4<}\right), 7.50(\mathrm{~d}$, $\left.\mathrm{J}=6.8 \mathrm{~Hz}, 1 \mathrm{H}_{>}, \operatorname{TrpNH}_{>}\right), 7.65\left(\mathrm{~d}, \mathrm{~J}=8.0 \mathrm{~Hz}, 1 \mathrm{H}_{>}, \operatorname{TrpArH} \mathrm{Ar}_{>}\right), 8.52\left(\mathrm{~d}, \mathrm{~J}=7.2 \mathrm{~Hz}, 1 \mathrm{H}<, \operatorname{TrpNH}_{<}\right), 8.91(\mathrm{~d}, \mathrm{~J}$ $\left.=7.2 \mathrm{~Hz}, 1 \mathrm{H}_{>}, \mathrm{PheNH}_{>}\right), 8.96\left(\mathrm{~d}, \mathrm{~J}=6.4 \mathrm{~Hz}, 1 \mathrm{H}_{<}, \mathrm{PheNH}_{<}\right), 10.64\left(\mathrm{~s}, 1 \mathrm{H}_{<}, \operatorname{TrpArH}_{1<}\right), 10.75\left(\mathrm{~s}, 1 \mathrm{H}_{>}\right.$, TrpArH $\mathrm{A}_{1}$ ); ${ }^{13} \mathrm{C}$ NMR (two sets of signals) $\delta: 22.0,23.2,25.8,26.7,28.0,29.9,32.5,34.5,35.8,36.2,37.2$, 47.4, 55.0, 55.8, 56.2, 57.0, 58.5, 59.5, 60.6, 64.6, 111.6, 112.2, 119.1, 119.4, 124.4, 126.3, 127.3, 129.1, $129.8,129.9,137.0,138.0,138.3,138.8,170.8,171.6,171.7,171.8,172.0,174.5,175.5 ;$ ESI MS $(\mathrm{m} / \mathrm{z})$ 
$502.2[\mathrm{M}+1]$, calcd: 502.2; Elem. Anal. for $\mathrm{C}_{28} \mathrm{H}_{31} \mathrm{~N}_{5} \mathrm{O}_{4}$ : calcd C 67.05, H 6.23, N 13.96; found C 67.14, H 6.19, N 14.0.

c[GABA-D-Pro-Phe-Trp] 10. ${ }^{1} \mathrm{H}$ NMR $\delta:$ 1.54-1.62 (m, 2H, GABAH $\left.\beta+\mathrm{D}-\mathrm{ProH} \gamma\right), 1.62-1.72$ (m, 2H, GABAH $\beta+\mathrm{D}-\operatorname{ProH} \beta), 1.98$ (m, 1H, GABAH $\alpha), 2.04$ (m, 1H, D-ProH $\gamma), 2.12-2.21$ (m, 2H, D-ProH $\beta+\mathrm{D}-$ ProH $\gamma$ ), 2.42 (m, 1H, GABAH $\alpha$ ), 2.67 (m, 1H, GABAH $\gamma$ ), 2.74 (dd, J = 6.0, 13.6 Hz, 1H, PheH $\beta$ ), 2.86 (dd, $\mathrm{J}=4.8,13.6 \mathrm{~Hz}, 1 \mathrm{H}, \mathrm{PheH} \beta), 3.03$ (dd, $\mathrm{J}=9.2,14.8, \mathrm{~Hz}, 1 \mathrm{H}, \operatorname{TrpH} \beta), 3.20-3.28$ (m, 2H, D-ProH $\delta$ ), 3.35 (m, $1 \mathrm{H}, \operatorname{TrpH} \beta), 3.45$ (m, 1H, GABAH $\gamma), 4.11(\mathrm{~m}, 1 \mathrm{H}, \mathrm{PheH} \alpha), 4.16(\mathrm{~m}, 1 \mathrm{H}, \operatorname{TrpH} \alpha), 4.38$ (dd, J = 2.2, $6.8 \mathrm{~Hz}$,

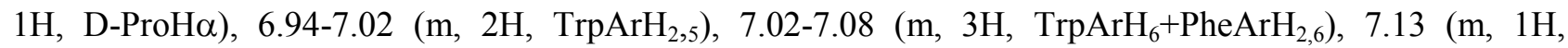
PheArH $_{4}$ ), 7.16-7.21 (m, 2H, PheArH $\left.{ }_{3,5}\right), 7.33$ (d, J = 8.0 Hz, 1H, TrpArH ${ }_{7}$ ), 7.42 (br.t, 1H, GABANH), 7.53 (d, J = 7.6 Hz, 1H, TrpArH ${ }_{4}$ ), 8.31 (br.d, $\left.1 \mathrm{H}, \operatorname{TrpNH}\right), 8.67$ (br.d, $\left.1 \mathrm{H}, \mathrm{PheNH}\right), 10.76$ (s, $\left.\left.1 \mathrm{H}, \operatorname{TrpArH}\right)_{1}\right) ;{ }^{13} \mathrm{C}$ NMR $\delta$ : 23.0, 23.1, 25.1, 26.4, 29.6, 32.2, 37.1, 47.2, 49.5, 57.5, 60.0, 70.7, 112.0, 112.2, 119.1, 119.2, $121.8,124.0,127.3,128.3,129.1,129.7,137.0,138.1,171.4,172.4,173.4,174.4 ;$ ESI MS (m/z) 516.5 [M+1], calcd: 516.3; Elem. Anal. for $\mathrm{C}_{29} \mathrm{H}_{33} \mathrm{~N}_{5} \mathrm{O}_{4}$ : calcd C 67.55, H 6.45, N 13.58; found C 67.49, H 6.51, N 13.65 .
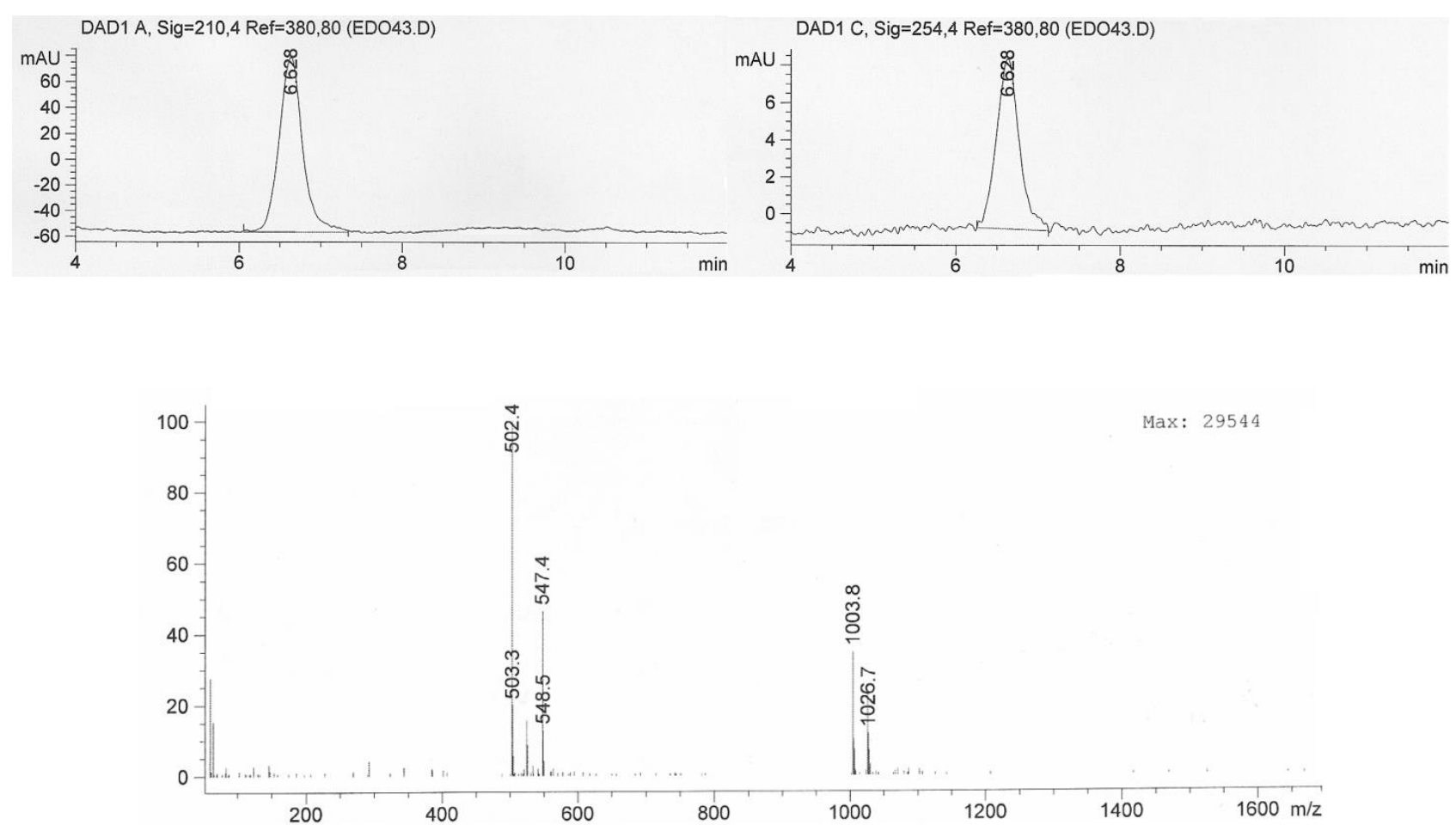

Figure S1 Top: RP-HPLC of 9 on a C18 column Phenomenex Gemini 3u C18 $110 \AA 10033.0$ mm, mobile phase from 9:1 $\mathrm{H}_{2} \mathrm{O} / \mathrm{CH}_{3} \mathrm{CN}$ to $2: 8 \mathrm{H}_{2} \mathrm{O} / \mathrm{CH}_{3} \mathrm{CN}$ in $20 \mathrm{~min}$ at a flow rate of $1.0 \mathrm{~mL} \mathrm{~min}{ }^{-1}$. Bottom: ESI MS of 9 performed on a single quadrupole HP 1100MSD detector. 

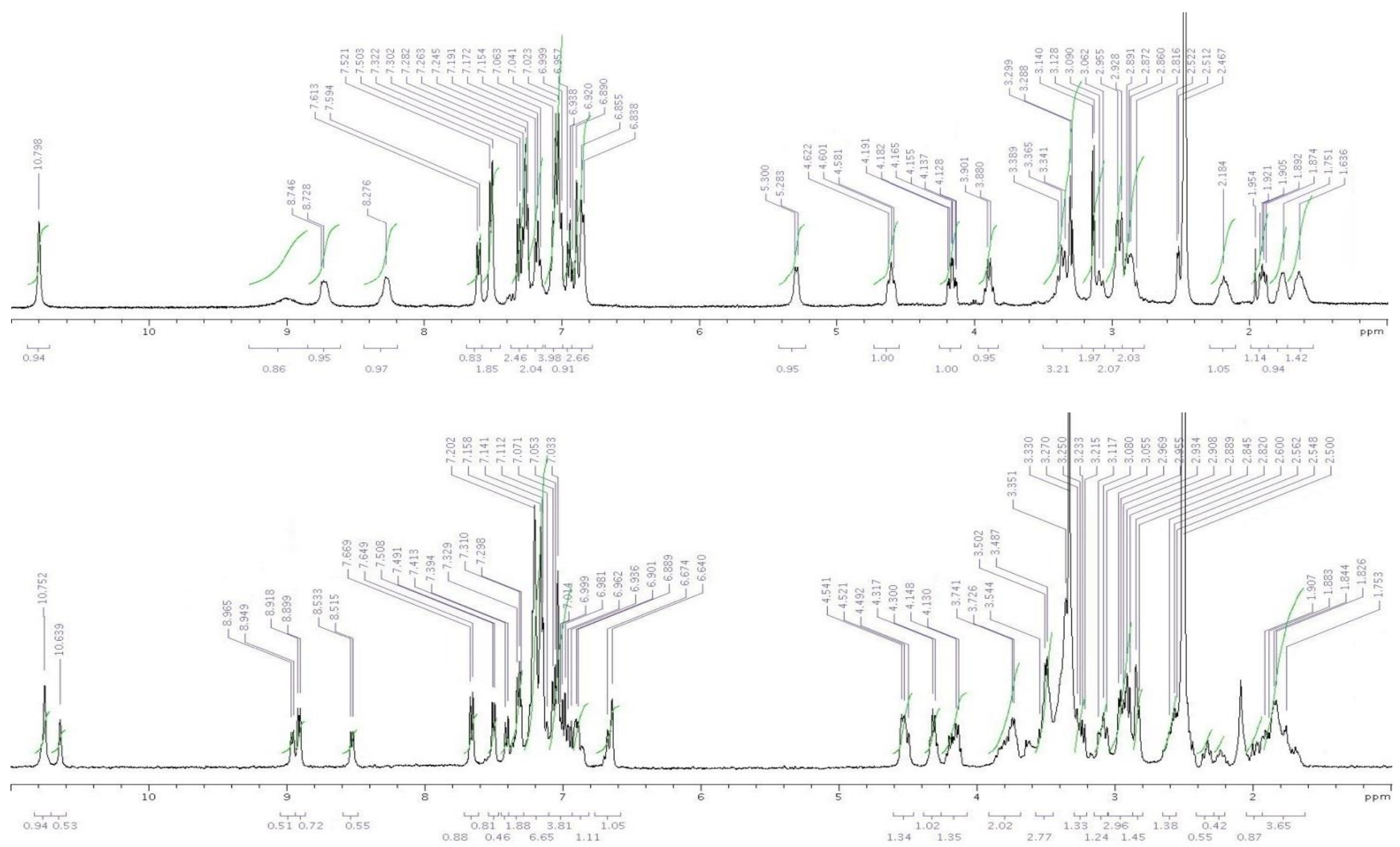

Figure S2 $400 \mathrm{MHz}{ }^{1} \mathrm{H}$ NMR of c[Phe-D-Pro-Phe-Trp] CJ-15,208 1 and c[ $\beta$-Ala-D-Pro-Phe-Trp] 9, 0.01 M in 8:2 [D6]DMSO/H ${ }_{2} \mathrm{O}$ at r.t. (water suppression). 
Receptor Binding to Cloned Human OR. Displacement binding assays were performed in HEK-293 cells stably expressing human MOR, DOR, or KOR obtained as previously reported. ${ }^{1,2,3,4}$ Cell surface human MOR were measured on intact cells using $\left[{ }^{3} \mathrm{H}\right]$ DAMGO $(0.1-5.0 \mathrm{nM})$ as radioligand and naloxone $(30 \mu \mathrm{M})$ to determine nonspecific binding. For displacement binding assays, HEK-293 cells expressing human MOR were incubated at $\mathrm{rt}$ for $2 \mathrm{~h}$ with $\left[{ }^{3} \mathrm{H}\right]$ DAMGO $(2.5 \mathrm{nM})$ in the presence or absence of compounds at various concentrations $\left(10^{-12}-10^{-4} \mathrm{M}\right.$; compound 5 and $\mathbf{1 0}$ were assayed up to $\left.10^{-2} \mathrm{M}\right)$; nonspecific binding was determined in the presence of naloxone $(30 \mu \mathrm{M})$. After incubation with the ligands, cells were washed in PBS (pH 7.4) and lysed with $0.1 \mathrm{~N} \mathrm{NaOH}$. Lysed samples were buffered with an equal amount of $0.1 \mathrm{~N} \mathrm{HCl}$ and left in scintillation fluid for $8 \mathrm{~h}$ before counting. Cell membranes from DOR and KOR expressing HEK293 cells were prepared as previously reported. ${ }^{1,2,3,4}$ Receptor binding assays were carried out by using $\left[{ }^{3} \mathrm{H}\right]$ diprenorphine to label DOR and $\left[{ }^{3} \mathrm{H}\right] \mathrm{U} 69,593$ (see Figure S3) to label KOR and by incubating the membrane preparations at $25^{\circ} \mathrm{C}$ for $90 \mathrm{~min}$ in buffer containing $100 \mathrm{mM}$ Tris- $\mathrm{HCl}$ and $0.3 \% \mathrm{BSA}$. For saturation binding assays, the concentrations of $\left[{ }^{3} \mathrm{H}\right]$ diprenorphine and $\left[{ }^{3} \mathrm{H}\right] \mathrm{U} 69,593$ ranged from $40 \mathrm{pM}$ to 3 $\mathrm{nM}$ and from $20 \mathrm{pM}$ to $5 \mathrm{nM}$, respectively. For competition binding assays, the concentration of $\left[{ }^{3} \mathrm{H}\right]$ diprenorphine or $\left[{ }^{3} \mathrm{H}\right] \mathrm{U} 69,593$ was 1 and $2 \mathrm{nM}$, respectively. Nonspecific binding was determined in the presence of $10 \mu \mathrm{M}$ DPDPE (DOR) or $10 \mu \mathrm{M}$ U50,488 (KOR) and corresponded to $8-12 \%$ and $12-15 \%$ of total $\left[{ }^{3} \mathrm{H}\right]$ diprenorphine and $\left[{ }^{3} \mathrm{H}\right] \mathrm{U} 69,593$ binding, respectively. Triplicate determinations were made for each experiment. Reactions were terminated by filtration through Whatman GF/C filters presoaked with $0.3 \%$ polyethylenimine, which were washed three times with $5 \mathrm{~mL}$ of ice-cold buffer containing $50 \mathrm{mM}$ Tris-HCl, $\mathrm{pH}$ 7.4. The radioactivity trapped was determined by liquid scintillation spectrometry. Data from at least three independent experiments were fitted by nonlinear regression analysis using GraphPad Prism. $K_{\mathrm{i}}$ values were calculated from the $\mathrm{IC}_{50}$ using the Cheng-Prusoff equation. $\mathrm{IC}_{50}$ values represent mean values from no less than four experiments. $\mathrm{IC}_{50}$ values, relative potency estimates, and their associated standard errors were determined by fitting the data to the Hill equation by a computerized nonlinear least squares method.

The reference compounds DAMGO (H-Tyr-D-Ala-Gly-NMePhe-Glyol), ${ }^{5}$ DPDPE (H-Tyr-c[D-Pen-GlyPhe-D-Pen]-OH ), ${ }^{6}$ and U50,488 (see Figure S3), ${ }^{7}$ showed $K$ i values in the nM range and high selectivity to the respective receptors (Table 1), as expected.
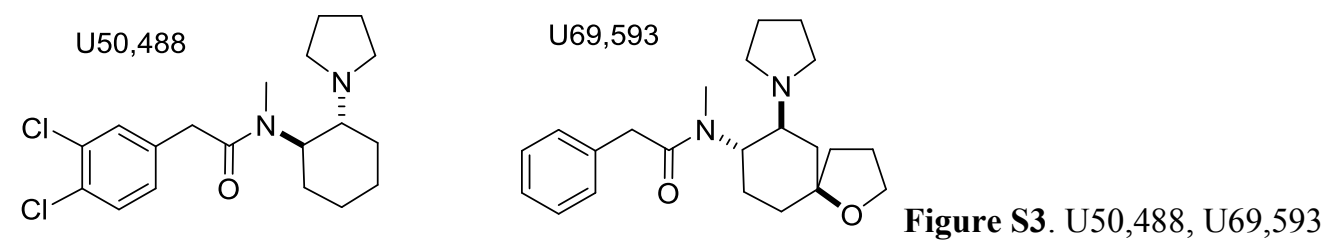

Determination of inhibition of cAMP accumulation for 9 and 10. The agonist activity of 9 and $\mathbf{1 0}$ was determined by measuring the inhibition of forskolin-stimulated cAMP accumulation in whole HEK-293 cells stably expressing MOR or DOR. Cells were grown at $37^{\circ} \mathrm{C}$ and $5 \% \mathrm{CO}_{2}$ in MEM, $2 \mathrm{mM}$ Gln, and $1 \times$ nonessential amino acids supplemented with $10 \%$ FBS. Samples in a $75 \mathrm{~cm}^{2}$ flask at $95-100 \%$ confluence 
were split into 24 wells and incubated overnight. When the confluence became $85-95 \%$, the medium was removed and the cells were washed three times with PBS; thereafter, cells were incubated in serum-free medium containing $0.5 \mathrm{mM}$ 3-isobutyl-1-methylxanthine and exposed for $15 \mathrm{~min}$ to $10 \mu \mathrm{M}$ forskolin without and with each compound $(0.001 \mathrm{nM}$ to $100 \mu \mathrm{M})$ at $37^{\circ} \mathrm{C}$. Cells were then lysed in $0.1 \mathrm{~N} \mathrm{HCl}$, scraped off, and centrifuged (2000 g, $5 \mathrm{~min}$ ). Supernatants were assayed for cAMP concentration by using a cAMP EIA kit (Caiman Chemicals) according to the manufacturer's instructions. The reference compounds morphine, DAMGO and DPDPE, inhibited forskolin-induced cAMP accumulation, with $\mathrm{IC}_{50}$ values of $4.3 \mathrm{nM}, 19 \mathrm{nM}$ and $1.6 \mathrm{nM}$, and $\mathrm{E}_{\max }$ of $77 \%, 95 \%$ and $89 \%$, respectively, in agreement to the literature. ${ }^{8}$

To assess any potential activity as antagonists of the compounds under investigation, HEK-293 cells expressing DOR, KOR or MOR were incubated at $37^{\circ} \mathrm{C}$ in serum-free medium containing $0.5 \mathrm{mM} 3$ isobutyl-1-methylxanthine and exposed for $15 \mathrm{~min}$ to $10 \mu \mathrm{M}$ forskolin without and with $10 \mu \mathrm{M}$ of the reference agonist ligand ( DAMGO for MOR; U50,488 for KOR and DPDPE for DOR) and 10 (0.001 nM$100 \mu \mathrm{M})$ concentrations of the purported antagonist. Each well was determined individually. The triplicates were averaged, and $\mathrm{IC}_{50}$ values were determined. Activities are expressed as percent inhibition of forskolininduced cAMP production.

Assessment of enzymatic stability. The enzymatic stability of 9 was estimated by incubation in mouse serum for 3 h. ${ }^{9}$ During this period, samples of the incubation mixture were withdrawn and analyzed to check peptide hydrolysis. These assays were carried out in triplicate and repeated three times. To set the experiments, $10 \mu \mathrm{L}$ aliquots of $10 \mathrm{mM}$ peptide stock solution in Tris buffer $\mathrm{pH} 7.4$ were added to $190 \mu \mathrm{L}$ of mouse serum (Sigma-Aldrich) at $37^{\circ} \mathrm{C}$. Aliquots of $20 \mathrm{~mL}$ were withdrawn from the incubation mixtures and enzyme activity was terminated by precipitating proteins with $90 \mathrm{~mL}$ of glacial acetonitrile. Samples were then diluted with $90 \mathrm{~mL}$ of $0.5 \% \mathrm{AcOH}$ to prevent further enzymatic activity and centrifuged at $13,000 \times \mathrm{g}$ for 15 min. The supernatants were collected and the stability of peptide was determined by RP HPLC and ESI MS analysis. After 180 min, the CTPs were degraded $<5 \%$.

Animals and treatments Adult male CD-1 mice weighing 25-30 g were housed in a light- and temperaturecontrolled room (light on 08.00-20.00 h, temperature $24^{\circ} \mathrm{C}$ ) and had free access to food and water. This research was conducted in compliance with the guidelines of the Directive 2010/63/EU revising Directive 86/609/EEC on the protection of animals used for scientific purpose. The procedures employed in this study were approved by the Animal Care and Use Committee of the University of Bologna ( Prot. n. 29-IX/9, 25th July 2012) and conformed to the International Association for the Study of Pain (IASP) guidelines on ethical standards for investigations of experimental pain in animals. For ip injections, the compounds were dissolved in a $1: 1 \mathrm{v} / \mathrm{v}$ solution of propylene glycol and saline (vehicle) and injected in a volume of $0.1 \mathrm{ml} / 10 \mathrm{~g}$ body weight for ip administration. 
Visceral pain test. Antinociception was evaluated, in the different groups of mice placed individually in a large glass cylinder for observation, by counting stretching or writhing responses during a 10-min period, after ip injection of $\mathrm{AcOH}$ acid $(0.1 \mathrm{ml} / 10 \mathrm{~g}$ of a $0.6 \%, \mathrm{w} / \mathrm{v}$ solution in water). Each writhe typically consisted of a wave of contraction of the abdominal musculature followed by extension of the hind legs. Cyclopeptide 9 was administered before $\mathrm{AcOH}$ and the control group was treated with an equal amount of vehicle (propylene glycol and saline, 1:1 ratio) before administering the AcOH solution. The DOR selective antagonist naltrindole (NTD, $10 \mathrm{mg} / \mathrm{kg}$; ip), the KOR selective antagonist norbinaltorphimine (nor-BNI, 10 $\mathrm{mg} / \mathrm{kg}$; ip) and the not selective opioid antagonist naloxone (30 mg/kg; ip) were injected $15 \mathrm{~min}, 30 \mathrm{~min}$ and 10 min prior to administering compound $\mathbf{9}$, respectively.

Statistical analysis. Data are expressed as mean \pm SEM. Statistical significance of the data was estimated by a mixed two-factor analysis of variance (ANOVA) or by one-way ANOVA and Dunnett post hoc test. P $\leq 0.05$ was accepted as significant. The $\mathrm{EC}_{50}$ value and their $95 \%$ confidence limits (CL95) were generated by nonlinear curve fitting of the $\mathbf{9}$ and $\mathbf{1 0}$ dose-response data performed by Prism through a nonweighted iterative process (Prism v3.0, Graph Pad Software, Inc., San Diego, CA).

Conformational analysis. 2D ROESY experiments in [D6]DMSO/ $\mathrm{H}_{2} \mathrm{O}(8: 2)$ were performed in the phasesensitive mode at r.t., spin-locking field ( $\gamma \mathrm{b} 2)$ was $2000 \mathrm{~Hz}$, and mixing time was set to $250 \mathrm{~ms}$; spectra were processed in the hypercomplex approach; peaks were calibrated on DMSO. Only ROESY-derived constraints were included in the restrained MD. ${ }^{10}$ Cross-peak intensities were classified as very strong, strong, medium, and weak, and were associated with distances of 2.3, 2.7, 3.3, and 5.0 $\AA$, respectively. ${ }^{2}$ The intensities of the cross peaks arising from protons separated by known distances (e.g., geminal) were found to match with these associations. Geminal and other clear correlations were discarded as constraints. For the absence of $\mathrm{H \alpha}_{(i, i+l)}$ ROESY cross peaks, all of the $\omega$ bonds were set at $180^{\circ}$ (f constant: $16 \mathrm{kcal} \mathrm{mol}^{-1} \AA^{-2}$ ).

MD simulations. The restrained MD simulations were conducted at $300 \mathrm{~K}$ and $1 \mathrm{~atm}$ by using the AMBER force field ${ }^{11}$ in a $30 \times 30 \times 30 \AA$ box of standard TIP3P models of equilibrated water. ${ }^{12}$ Periodic boundary conditions were applied, a constant dielectric scale factor of 1 was used, and the cutoff distance for the nonbonded interactions was $12 \AA$. All water molecules with atoms that come closer than $2.3 \AA$ to a solute atom were eliminated. A $100 \mathrm{ps}$ simulation at $1200 \mathrm{~K}$ was used for generating 50 random structures that were subsequently subjected to a $50 \mathrm{ps}$ restrained $\mathrm{MD}$ with a $50 \%$ scaled force field at the same temperature, followed by 50 ps with full restraints (distance force constant of $7 \mathrm{kcalmol}^{-1} \AA \AA^{-2}$ ), after which the system was cooled in $20 \mathrm{ps}$ to $50 \mathrm{~K}$. Hydrogen-bond interactions were not included, nor were torsion angle restraints. The resulting structures were minimized with 3000 cycles of steepest descent and 3000 cycles of 
conjugated gradient (convergence of $0.01 \mathrm{kcal}^{-1} \mathrm{~mol}^{-1}$ ). The backbones of the structures were clustered by the rmsd analysis. ${ }^{10}$

Unrestrained $M D$ simulations ${ }^{10}$ were performed starting with the conformation derived from ROESY in a $30 \times 30 \times 30 \AA ̊$ box of standard TIP3P water for $10 \mathrm{~ns}$ at $298 \mathrm{~K}$ using periodic boundary conditions, at constant temperature and pressure (Berendsen scheme, ${ }^{13}$ bath relaxation constant of 0.2). For 1-4 scale factors, van der Waals and electrostatic interactions are scaled in AMBER to half their nominal value. The integration time step was set to $0.1 \mathrm{fs}$. The system coordinates were collected every picosecond.

Table S2. Non-obvious REOSY cross peaks for c[Phe ${ }^{1}$-D-Pro-Phe $\left.{ }^{3}-\mathrm{Trp}\right] \mathbf{1}$ in 8:2 [D6]DMSO/ $\mathrm{H}_{2} \mathrm{O}$; vs = very strong, $\mathrm{s}=$ strong, $\mathrm{m}=$ medium, $\mathrm{w}=$ weak.

\begin{tabular}{|c|c|c|c|}
\hline cross peak & intensity & cross peak & intensity \\
\hline $\mathrm{Phe}^{1} \mathrm{NH}-\mathrm{Phe}{ }^{1} \mathrm{H} \beta_{2.9}$ & $\mathrm{~m}$ & Phe ${ }^{1} \mathrm{NH}-\mathrm{Phe}{ }^{1} \mathrm{H} \beta_{3.0}$ & $\mathrm{~m}$ \\
\hline $\mathrm{Phe}^{1} \mathrm{NH}-\mathrm{Phe}{ }^{1} \mathrm{H} \alpha$ & $\mathrm{m}$ & $\mathrm{Phe}^{1} \mathrm{NH}-\mathrm{Phe}{ }^{3} \mathrm{H} \alpha$ & $\mathrm{m}$ \\
\hline Phe ${ }^{1}$ NH-D-Pro $\alpha$ & $\mathrm{m}$ & $\mathrm{Phe}^{1} \mathrm{NH}-\mathrm{TrpNH}$ & $\mathrm{s}$ \\
\hline $\operatorname{TrpNH}-\operatorname{TrpH} \beta_{2.5}$ & $\mathrm{w}$ & TrpNH-TrpH $\beta_{2.9}$ & $\mathrm{~s}$ \\
\hline TrpNH-Phe ${ }^{3} \mathrm{H} \beta_{3.0}$ & $\mathrm{~m}$ & TrpNH-Phe ${ }^{1} \mathrm{H} \alpha$ & $\mathrm{W}$ \\
\hline TrpNH-TrpH $\alpha$ & $\mathrm{m}$ & TrpNH-TrpArH2 & $\mathrm{W}$ \\
\hline TrpNH-TrpArH4 & $\mathrm{m}$ & TrpNH-Phe ${ }^{3} \mathrm{NH}$ & $\mathrm{s}$ \\
\hline $\mathrm{Phe}^{3} \mathrm{NH}-\mathrm{TrpH} \beta_{2.5}$ & $\mathrm{~m}$ & $\mathrm{Phe}^{3} \mathrm{NH}-\mathrm{Phe}{ }^{3} \mathrm{H} \beta_{3.0}$ & s \\
\hline $\mathrm{Phe}^{3} \mathrm{NH}-\mathrm{Phe}{ }^{3} \mathrm{H} \beta_{3.2}$ & $\mathrm{~s}$ & Phe ${ }^{3} \mathrm{NH}-\mathrm{TrpH} \alpha$ & $\mathrm{w}$ \\
\hline $\mathrm{Phe}^{3} \mathrm{NH}-\mathrm{Phe}{ }^{3} \mathrm{H} \alpha$ & $\mathrm{m}$ & Phe ${ }^{3}$ NH-D-Pro $\alpha$ & s \\
\hline $\mathrm{Phe}^{3} \mathrm{NH}-\mathrm{Phe}^{3} \mathrm{ArH}$ & $\mathrm{w}$ & TrpArH4-TrpH $\beta_{2.5}$ & $\mathrm{~W}$ \\
\hline $\operatorname{TrpArH4-TrpH} \beta_{2.9}$ & s & TrpArH4-TrpH $\alpha$ & $\mathrm{m}$ \\
\hline $\mathrm{Phe}^{3} \mathrm{ArH} 2,6-\mathrm{TrpH} \beta_{2.5}$ & $\mathrm{w}$ & $\mathrm{Phe}^{3} \mathrm{ArH} 2,6-\mathrm{Phe}^{3} \mathrm{H} \beta_{3.0}$ & $\mathrm{~s}$ \\
\hline $\mathrm{Phe}^{3} \mathrm{ArH} 2,6-\mathrm{Phe}^{3} \mathrm{H} \beta_{3.2}$ & $\mathrm{~m}$ & $\mathrm{Phe}^{3} \mathrm{ArH} 2,6-\mathrm{TrpH} \alpha$ & $\mathrm{w}$ \\
\hline $\mathrm{Phe}^{3} \mathrm{ArH} 2,6-\mathrm{Phe}^{3} \mathrm{H} \alpha$ & $\mathrm{s}$ & $\mathrm{Phe}^{3} \mathrm{ArH} 2,6-\mathrm{D}-\mathrm{ProH} \alpha$ & $\mathrm{W}$ \\
\hline $\mathrm{Phe}^{3} \mathrm{ArH} 3,5-\operatorname{TrpH} \beta_{2.5}$ & $\mathrm{w}$ & $\mathrm{Phe}^{3} \mathrm{ArH} 3,5-\mathrm{TrpH} \beta_{2.9}$ & $\mathrm{w}$ \\
\hline $\mathrm{Phe}^{3} \mathrm{ArH} 3,5-\mathrm{Phe}^{3} \mathrm{H} \beta_{3.0}$ & $\mathrm{~m}$ & $\mathrm{Phe}^{3} \mathrm{ArH} 3,5-\mathrm{Phe}^{3} \mathrm{H} \beta_{3.2}$ & $\mathrm{w}$ \\
\hline $\mathrm{Phe}^{3} \mathrm{ArH} 3,5-\mathrm{Phe}^{3} \mathrm{H} \alpha$ & $\mathrm{w}$ & $\mathrm{Phe}^{3} \mathrm{ArH} 3,5-\mathrm{D}-\mathrm{ProH} \alpha$ & $\mathrm{W}$ \\
\hline $\mathrm{Phe}^{3} \mathrm{ArH} 4-\mathrm{Phe}^{3} \mathrm{H} \beta_{3.0}$ & $\mathrm{~m}$ & $\mathrm{Phe}^{3} \mathrm{ArH} 4-\mathrm{Phe}^{3} \mathrm{H} \beta_{3.2}$ & $\mathrm{~m}$ \\
\hline $\mathrm{Phe}^{3} \mathrm{ArH} 4-\mathrm{Phe}^{3} \mathrm{H} \alpha$ & w & $\mathrm{Phe}^{1} \mathrm{ArH} 3,4,5-\mathrm{Phe}^{1} \mathrm{H} \beta_{2.9}$ & $\mathrm{~m}$ \\
\hline $\mathrm{Phe}^{1} \mathrm{ArH} 3,4,5-\mathrm{Phe}{ }^{1} \mathrm{H} \beta_{3.0}$ & $\mathrm{~m}$ & $\mathrm{Phe}^{1} \mathrm{ArH} 3,4,5-\mathrm{Phe}^{1} \mathrm{H} \alpha$ & $\mathrm{m}$ \\
\hline $\mathrm{Phe}^{1} \mathrm{ArH} 3,4,5-\mathrm{Phe}^{3} \mathrm{H} \alpha$ & w & $\mathrm{Phe}^{1} \mathrm{ArH} 3,4,5-\mathrm{D}-\mathrm{ProH} \alpha$ & $\mathrm{w}$ \\
\hline $\operatorname{TrpArH2-TrpH} \beta_{2.5}$ & $\mathrm{~m}$ & $\operatorname{TrpArH2-TrpH} \beta_{2.9}$ & $\mathrm{~m}$ \\
\hline $\operatorname{TrpArH} 2-\mathrm{Phe}^{1} \mathrm{H} \beta_{3.0}$ & $\mathrm{w}$ & $\operatorname{TrpArH2-TrpH\alpha }$ & $\mathrm{m}$ \\
\hline
\end{tabular}




\begin{tabular}{|c|c|c|c|}
\hline $\mathrm{Phe}^{1} \mathrm{ArH} 2,6-\mathrm{Ph} \mathrm{e}^{1} \mathrm{H} \beta_{2.9}$ & $\mathrm{~m}$ & $\mathrm{Phe}^{1} \mathrm{ArH} 2,6-\mathrm{Phe}{ }^{1} \mathrm{H} \beta_{3.0}$ & $\mathrm{~m}$ \\
\hline $\mathrm{Phe}^{1} \mathrm{ArH} 2,6-\mathrm{Phe}{ }^{1} \mathrm{H} \alpha$ & $\mathrm{s}$ & D-ProH $\alpha-P h e^{3} H \beta_{3.0}$ & $\mathrm{~m}$ \\
\hline D-ProH $\alpha-P h{ }^{3} \mathrm{H} \beta_{3.2}$ & $\mathrm{~s}$ & D-ProH $\alpha-P h{ }^{1} \mathrm{H} \alpha$ & $\mathrm{w}$ \\
\hline D-ProH $\alpha-\operatorname{TrpH} \alpha$ & $\mathrm{w}$ & $\mathrm{Phe}^{3} \mathrm{H} \alpha-\mathrm{Phe}{ }^{3} \mathrm{H} \beta_{3.0}$ & $\mathrm{~s}$ \\
\hline $\mathrm{Phe}^{3} \mathrm{H} \alpha-\mathrm{Phe}{ }^{3} \mathrm{H} \beta_{3.2}$ & $\mathrm{~m}$ & $\operatorname{TrpH} \alpha-\operatorname{TrpH} \beta_{2.5}$ & vs \\
\hline $\operatorname{TrpH} \alpha-\operatorname{TrpH} \beta_{2.9}$ & $\mathrm{~m}$ & Phe ${ }^{1} H \alpha-D-P r o H \beta_{2.0}$ & w \\
\hline $\mathrm{Phe}^{1} \mathrm{H} \alpha-\mathrm{D}-\mathrm{ProH} \beta_{2.2}$ & $\mathrm{~W}$ & $\mathrm{Phe}^{1} \mathrm{H} \alpha-\mathrm{Phe}{ }^{1} \mathrm{H} \beta_{2.9}$ & $\mathrm{~m}$ \\
\hline $\mathrm{Phe}^{1} \mathrm{H} \alpha-\mathrm{Phe}{ }^{1} \mathrm{H} \beta_{3.0}$ & $\mathrm{~m}$ & & \\
\hline
\end{tabular}

Table S3. Non-obvious REOSY cross peaks for the major conformer A of c[ $\beta$-Ala-D-Pro-Phe-Trp] 9 in 8:2 [D6]DMSO $/ \mathrm{H}_{2} \mathrm{O}$; vs = very strong, $\mathrm{s}=$ strong, $\mathrm{m}=$ medium, $\mathrm{w}=$ weak.

\begin{tabular}{|c|c|c|c|}
\hline cross peak & intensity & cross peak & intensity \\
\hline PheNH-PheH $\beta$ & $\mathrm{s}$ & PheNH-PheNH & $\mathrm{m}$ \\
\hline PheNH-D-ProH $\alpha$ & vs & PheNH-PheArH2,6 & $\mathrm{w}$ \\
\hline PheNH-TrpNH & $\mathrm{s}$ & TrpArH4-PheH $\beta$ & $\mathrm{w}$ \\
\hline TrpArH4-TrpH $\beta_{3.0}$ & $\mathrm{~s}$ & $\operatorname{TrpArH4} 4-\operatorname{TrpH} \beta_{3.3}$ & $\mathrm{w}$ \\
\hline TrpArH4- $\beta$-AlaH $\beta$ & $\mathrm{w}$ & TrpArH4-TrpH $\alpha$ & $\mathrm{s}$ \\
\hline TrpNH-PheH $\beta$ & $\mathrm{s}$ & TrpNH-TrpH $\beta_{3.0}$ & $\mathrm{~m}$ \\
\hline TrpNH-TrpH $\beta_{3.3}$ & $\mathrm{w}$ & TrpNH-PheH $\alpha$ & $\mathrm{w}$ \\
\hline TrpNH-TrpH $\alpha$ & $\mathrm{s}$ & TrpNH-D-ProH $\alpha$ & $\mathrm{w}$ \\
\hline TrpNH- $\beta$-AlaNH & $\mathrm{s}$ & TrpNH-TrpArH2 & $\mathrm{w}$ \\
\hline PheArH2,6-PheH $\alpha$ & $\mathrm{s}$ & $\operatorname{TrpArH} 2-\operatorname{TrpH} \beta_{3.0}$ & $\mathrm{~m}$ \\
\hline $\operatorname{TrpArH} 2-\operatorname{TrpH} \beta_{3.3}$ & $\mathrm{w}$ & TrpArH2-TrpH $\alpha$ & $\mathrm{m}$ \\
\hline TrpArH7-PheH $\beta$ & $\mathrm{w}$ & $\beta$-AlaNH- $\beta$-AlaH $\alpha_{2.5}$ & $\mathrm{w}$ \\
\hline$\beta$-AlaNH- $\beta$-AlaH $\alpha_{2.6}$ & $\mathrm{~m}$ & $\beta$-AlaNH- $\beta$-AlaH $\beta_{3.0}$ & vs \\
\hline$\beta$-AlaNH- $\beta$-AlaH $\beta_{3.8}$ & $\mathrm{~s}$ & $\beta$-AlaNH-D-ProH $\delta$ & $\mathrm{w}$ \\
\hline$\beta$-AlaNH-PheH $\alpha$ & $\mathrm{w}$ & $\beta$-AlaNH-TrpH $\alpha$ & vs \\
\hline D-ProH $\alpha-\operatorname{TrpH} \alpha$ & $\mathrm{m}$ & TrpH $\alpha-\mathrm{D}-\operatorname{ProH} \beta$ & $\mathrm{w}$ \\
\hline $\operatorname{TrpH\alpha } \alpha-\operatorname{TrpH} \beta_{3.0}$ & $\mathrm{~s}$ & $\operatorname{TrpH} \alpha-\operatorname{TrpH} \beta_{3.3}$ & $\mathrm{~s}$ \\
\hline TrpH $\alpha-\mathrm{D}-\mathrm{ProH} \delta$ & $\mathrm{w}$ & TrpH $\alpha-\mathrm{D}-\mathrm{ProH} \alpha$ & $\mathrm{m}$ \\
\hline PheH $\alpha-\operatorname{TrpH} \beta_{3.3}$ & $\mathrm{w}$ & PheH $\alpha$-D-ProH $\delta$ & $\mathrm{w}$ \\
\hline$\beta-\mathrm{AlaH} \beta_{3.8}-\beta-\mathrm{AlaH} \alpha_{2.5}$ & $\mathrm{~s}$ & $\beta-\mathrm{AlaH} \beta_{3.8}-\beta-\mathrm{AlaH \alpha}_{2.6}$ & $\mathrm{w}$ \\
\hline$\beta-\mathrm{AlaH} \beta_{3.8}-\operatorname{TrpH} \beta_{3.3}$ & $\mathrm{w}$ & $\beta$-AlaH $\beta_{3.8}$-D-ProH $\delta$ & $\mathrm{m}$ \\
\hline D-ProH $\delta-\beta-A l a H \alpha_{2.5}$ & $\mathrm{w}$ & D-ProH $\delta-\beta-\mathrm{AlaH \alpha}_{2.6}$ & $\mathrm{~s}$ \\
\hline D-ProH $\delta-\beta-A l a H \beta_{3.0}$ & $\mathrm{~m}$ & D-ProH $\delta$-TrpH $\beta_{3.3}$ & w \\
\hline
\end{tabular}


Table S4. Non-obvious REOSY cross peaks for the minor conformer $\mathbf{B}$ of c[ $\beta$-Ala-D-Pro-Phe-Trp] 9 in 8:2 [D6]DMSO $/ \mathrm{H}_{2} \mathrm{O}$; vs = very strong, $\mathrm{s}=$ strong, $\mathrm{m}=$ medium, $\mathrm{w}=$ weak.

\begin{tabular}{|c|c|c|c|}
\hline cross peak & intensity & cross peak & intensity \\
\hline PheNH-D-ProH $\beta_{1.8}$ & $\mathrm{w}$ & PheNH-PheH $\beta$ & $\mathrm{s}$ \\
\hline PheNH-PheH $\alpha$ & $\mathrm{m}$ & PheNH-D-ProH $\alpha$ & vs \\
\hline PheNH-PheArH2,6 & $\mathrm{w}$ & PheNH-TrpNH & $\mathrm{w}$ \\
\hline TrpNH-PheH $\beta$ & $\mathrm{w}$ & $\operatorname{TrpNH}-\mathrm{TrpH} \beta_{3.1}$ & $\mathrm{w}$ \\
\hline TrpNH-TrpH $\alpha$ & vs & TrpNH-PheH $\alpha$ & vs \\
\hline TrpNH- $\beta$-AlaNH & $\mathrm{s}$ & $\operatorname{TrpArH4} 4-\operatorname{TrpH} \beta_{2.9}$ & w \\
\hline TrpArH4-TrpH $\beta_{3.2}$ & $\mathrm{~m}$ & TrpArH4-TrpH $\alpha$ & $\mathrm{s}$ \\
\hline PheArH2,6-PheH $\alpha$ & $\mathrm{s}$ & PheArH2,6-D-ProH $\alpha$ & $\mathrm{m}$ \\
\hline TrpArH7-PheH $\beta$ & $\mathrm{m}$ & TrpArH2-PheH $\beta$ & $\mathrm{w}$ \\
\hline $\operatorname{TrpArH} 2-\operatorname{TrpH} \beta_{3.2}$ & vs & $\operatorname{TrpArH2-TrpH\alpha }$ & s \\
\hline$\beta$-AlaNH-TrpH $\alpha$ & $\mathrm{m}$ & $\beta$-AlaNH- $\beta$-AlaH $\alpha_{2.0}$ & $\mathrm{~s}$ \\
\hline$\beta$-AlaNH- $\beta$-AlaH $\beta_{3.9}$ & $\mathrm{~m}$ & $\beta$-AlaNH-D-ProH $\alpha$ & $\mathrm{w}$ \\
\hline D-ProH $\alpha-P h e H \alpha$ & $\mathrm{m}$ & PheH $\alpha-\mathrm{D}-\mathrm{ProH} \gamma$ & $\mathrm{w}$ \\
\hline PheH $\alpha$-D-ProH $\delta_{3.4}$ & $\mathrm{w}$ & $\beta-\mathrm{AlaH} \beta_{3.9}-\beta-\mathrm{AlaH} \alpha_{2.0}$ & $\mathrm{w}$ \\
\hline$\beta-\mathrm{AlaH} \beta_{3.9}-\beta-\mathrm{AlaH} \alpha_{2.4}$ & $\mathrm{~s}$ & TrpH $\alpha-\mathrm{D}-\mathrm{ProH} \delta$ & $\mathrm{w}$ \\
\hline
\end{tabular}

Table S5. Non-obvious REOSY cross peaks for c[GABA-D-Pro-Phe-Trp] 10 in 8:2 [D6]DMSO/ $\mathrm{H}_{2} \mathrm{O}$; vs = very strong, $\mathrm{s}=$ strong, $\mathrm{m}=$ medium, $\mathrm{w}=$ weak.

\begin{tabular}{|c|c|c|c|}
\hline cross peak & intensity & cross peak & intensity \\
\hline TrpArH1-PheArH4 & $\mathrm{w}$ & PheNH-D-ProH $\beta_{1.7}$ & $\mathrm{~m}$ \\
\hline PheNH-PheH $\beta_{2.9}$ & $\mathrm{~s}$ & PheNH-D-ProH $\delta$ & $\mathrm{w}$ \\
\hline PheNH-PheH $\alpha$ & $\mathrm{m}$ & PheNH-D-ProH $\alpha$ & vs \\
\hline PheNH-PheArH2,6 & $\mathrm{w}$ & PheNH-TrpNH & $\mathrm{w}$ \\
\hline $\operatorname{TrpNH}-\operatorname{TrpH} \beta_{3.0}$ & $\mathrm{~m}$ & TrpNH-PheH $\alpha$ & $\mathrm{s}$ \\
\hline TrpNH-TrpH $\alpha$ & $\mathrm{s}$ & TrpNH-TrpArH4 & $\mathrm{m}$ \\
\hline TrpNH-GABANH & $\mathrm{s}$ & TrpArH4-GABAH $\beta_{1.5}$ & w \\
\hline TrpArH4-GABAH $\alpha_{2.4}$ & $\mathrm{w}$ & $\operatorname{TrpArH4-TrpH} \beta_{3.0}$ & $\mathrm{~m}$ \\
\hline $\operatorname{TrpArH4-TrpH} \beta_{3.3}$ & $\mathrm{w}$ & TrpArH4-TrpH $\alpha$ & $\mathrm{m}$ \\
\hline TrpArH4-PheArH4 & $\mathrm{w}$ & TrpArH4-GABANH & $\mathrm{w}$ \\
\hline GABANH-GABAH $\alpha_{1.9}$ & $\mathrm{~m}$ & GABANH-GABAH $\gamma_{2.6}$ & $\mathrm{~s}$ \\
\hline GABANH-TrpH $\beta_{3.3}$ & $\mathrm{w}$ & GABANH-TrpH $\alpha$ & vs \\
\hline TrpArH7-GABAH $\gamma_{2.6}$ & $\mathrm{~m}$ & TrpArH7-D-ProH $\alpha$ & $\mathrm{m}$ \\
\hline PheArH3,5-D-ProH $\beta_{2.2}$ & $\mathrm{w}$ & PheArH3,5-PheH $\beta_{2.8}$ & $\mathrm{w}$ \\
\hline PheArH3,5-PheH $\alpha$ & $\mathrm{w}$ & PheArH4-GABAH $\alpha_{1.9}$ & $\mathrm{w}$ \\
\hline
\end{tabular}




\begin{tabular}{|c|c|c|c|}
\hline PheArH4-TrpH $\beta_{3.3}$ & $\mathrm{w}$ & PheArH4-TrpH $\alpha$ & $\mathrm{w}$ \\
\hline PheArH2,6-PheH $\beta_{2.7}$ & vs & PheArH2,6-PheH $\beta_{2.8}$ & vs \\
\hline PheArH2,6-PheH $\alpha$ & $\mathrm{s}$ & $\operatorname{TrpArH} 2-\operatorname{TrpH} \beta_{3.0}$ & $\mathrm{~m}$ \\
\hline $\operatorname{TrpArH} 2-\operatorname{TrpH} \beta_{3.3}$ & $\mathrm{~m}$ & $\operatorname{TrpArH2-TrpH\alpha }$ & $\mathrm{m}$ \\
\hline TrpArH5-PheH $\beta_{2.7}$ & $\mathrm{~m}$ & D-ProH $\alpha-G A B A H \alpha_{1.9}$ & $\mathrm{~m}$ \\
\hline $\operatorname{TrpH} \alpha-\operatorname{Trp} H \beta_{3.0}$ & $\mathrm{~m}$ & $\operatorname{TrpH} \alpha-\operatorname{Trp} H \beta_{3.3}$ & $\mathrm{~s}$ \\
\hline $\mathrm{PheH} \alpha-\mathrm{PheH} \beta_{2.7}$ & $\mathrm{~m}$ & $\mathrm{PheH} \alpha-\mathrm{PheH} \beta_{2.8}$ & vs \\
\hline GABAH $\gamma_{3.5}-\mathrm{GABAH}_{2.4}$ & $\mathrm{~m}$ & $\operatorname{TrpH} \beta_{3.0}-\mathrm{GABAH} \beta_{1.5}$ & $\mathrm{w}$ \\
\hline GABAH $\alpha_{2.4}$-D-ProH $\beta_{2.2}$ & $\mathrm{~m}$ & & \\
\hline
\end{tabular}

\section{References}

(1) Cardillo, G.; Gentilucci, L.; Tolomelli, A.; Spinosa, R.; Calienni, M.; Qasem, A. R.; Spampinato, S. Synthesis and evaluation of the affinity toward $\mu$-opioid receptors of atypical, lipophilic ligands based on the sequence c[Tyr-Pro-Trp-Phe-Gly]. J. Med. Chem. 2004, 47, 5198-5203.

(2) Gentilucci, L.; Tolomelli, A.; De Marco, R.; Spampinato, S.; Bedini, A.; Artali, R. The inverse type II beta-turn on D-Trp-Phe, a pharmacophoric motif for MOR agonists. Chem. Med. Chem. 2011, 6, 1640-1653.

(3) De Marco, R.; Tolomelli, A.; Spampinato, S.; Bedini, A.; Gentilucci, L. Opioid activity profiles of oversimplified peptides lacking in the protonable $N$-terminus. J. Med. Chem. 2012, 55, 10292-10296.

(4) De Marco, R.; Bedini, A.; Spampinato, S., Gentilucci, L. Synthesis of tripeptides containing D-Trp substituted at the indole ring, assessment of opioid receptor binding and in vivo central antinociception. $J$. Med. Chem. 2014, 57, 6861-6866.

(5) Harrison, C.; McNulty, S.; Smart, D.; Rowbotham, D. J.; Grandy, D. K.; Devi, L. A.; Lambert, D. G. The effects of endomorphin-1 and endomorphin-2 in CHO cells expressing recombinant $\mu$-opioid receptors and SH-SY5Y cells. Br. J. Pharmacol. 1999, 128, 472-478.

(6) Schmidt, H.; Vormfelde, S.; Klinder, K.; Gundert-Remy, U.; Gleiter, C. H.; Skopp, G.; Aderjan, R.; Fuhr, U. Affinities of dihydrocodeine and its metabolites to opioid receptors. Pharmacol. Toxicol. 2002, 91, $57-63$.

(7) Clark, J. A.; Pasternak, G. W. U50,488: a kappa-selective agent with poor affinity for $\mu 1$ opiate binding sites. Neuropharm. 1988, 27, 331-332. 
(8) Gong, J.; Strong, J.A.; Zhang, S.; Yue, X.; DeHaven, R.N.; Daubert, J.D.; Cassel, J.A.; Yu, G.; Mansson, E.; Yu, L. Endomorphins fully activate a cloned human mu opioid receptor. FEBS Lett. 1998, 439, 152-126.

(9) Bedini, A.; Baiula, M.; Gentilucci, L.; Tolomelli, A.; De Marco, R.; Spampinato, S. Peripheral antinociceptive effects of the cyclic endomorphin-1 analog c[YpwFG] in a mouse visceral pain model. Peptides 2010, 31, 2135-2140.

(10) HyperChem, Release 8.0.3, Hypercube Inc., 1115 NW 4th St. Gainesville, FL 32608, USA, 2007.

(11) Cornell, W. D.; Cieplak, P.; Bayly, C. I.; Gould, I. R.; Merz, K. M.; Ferguson, D. M.; Spellmeyer, D. C.; Fox, T.; Caldwell, J. W.; Kollman, P. A. A second generation force field for the simulation of proteins, nucleic acids, and organic molecoles. J. Am. Chem. Soc. 1995, 117, 5179-5197.

(12) Jorgensen, W. L.; Chandrasekhar, J.; Madura, J.; Impey, R. W.; Klein, M. L. Comparison of simple potential functions for simulating liquid water. J. Chem. Phys. 1983, 79, 926-935.

(13) Berendsen, H. J. C.; Postma, J. P. M.; van Gunsteren, W. F.; Di Nola, A.; Haak, J. R. Molecular dynamics with coupling to an external bath. J. Chem. Phys. 1984, 81, 3684-3690. 